\title{
Vasculitis due to ADA2 deficiency
}

INSERM

\section{Source}

INSERM. (1999). Orphanet: an online rare disease and orphan drug data base. Vasculitis due to ADA2 deficiency. ORPHA:404553

Vasculitis due to ADA2 deficiency is a rare, genetic, systemic and rheumatologic disease due to adenosine deaminase- 2 inactivating mutations, combining variable features of autoinflammation, vasculitis, and a mild immunodeficiency. Variable clinical presentation includes chronic or recurrent systemic inflammation with fever, livedo reticularis or racemosa, early-onset ischemic or hemorrhagic strokes, peripheral neuropathy, abdominal pain, hepatosplenomegaly, portal hypertension, cutaneous polyarteritis nodosa, variable cytopenia and immunoglobulin deficiency. 